\title{
PHYTOSANITATION OF MOUNTAIN PINE BEETLE INFECTED LODGEPOLE PINE USING DIELECTRIC FIELDS AT RADIO FREQUENCIES
}

\author{
Ciprian Lazarescu ${ }^{1}$, Colette Breuil ${ }^{1}$, Stavros Avramidis ${ }^{1, \wedge}$
}

\begin{abstract}
As an environmentally friendly alternative to chemical treatment, this research aimed to establish whether dielectric heating at high frequency of infested lodgepole pine (Pinus contorta) boards and logs, obtained from the mountain pine beetle devastated forests of British Columbia, can result in wood free of living fungi, nematodes and insects. The sample set contained 230 boards, $50 \times 150$ and $50 \times 100 \mathrm{~mm}^{2}$ in cross-section and $20 \operatorname{logs}, 200-300 \mathrm{~mm}$ in diameter; all tested specimens were roughly one meter long. The intention was to test the efficiency of two temperature/time combinations: $56^{\circ} \mathrm{C}$ for $30 \mathrm{~min}$ and $60^{\circ} \mathrm{C}$ for $15 \mathrm{~min}$ that were identified in past works as effective phytosanitary combinations. Data showed that both permutations eradicated all infestation levels and types. The electric field power density per treatment cycle ranged from 23 to $50 \mathrm{~kW} / \mathrm{m}^{3}$ and the total heating cycle varied from 42 to 116 minutes for all pest and wood type combinations tested.
\end{abstract}

Keywords: Dendroctonus ponderosae, dielectric heating, pasteurization, Pinus contorta, radio frequency.

\section{INTRODUCTION}

Dendroctonus ponderosae, also known as the mountain pine beetle (MPB), is a native bark beetle of western North America that can attack and breed in many pine species, including lodgepole (Pinus contorta), ponderosa (Pinus ponderosa), Scots (Pinus sylvestris) and lumber (Pinus flexilis) pines. MPB is specifically associated with ophiostomatoid fungi that the insect spreads in the tree phloem when it builds its gallery below the bark (Garas et al. 1979). Associated fungi colonize the phloem and sapwood and may participate in reducing the tree defense mechanisms during the one-year life cycle of the beetle. Depending on the MPB attack density, the degree of fungal colonization in a tree can vary significantly (Kim et al. 2005).

Despite measures taken to mitigate MPB adverse effects, recent climate changes in western Canada made a major contribution to the current epidemic expansion to the north of British Columbia (BC) and to Alberta (Williamson et al. 2009). It is expected that by 2013 this epidemic will eliminate $80 \%$ of the pine forests in BC (Nikiforuk 2007). Other researchers have indicated that the beetle has been able to attack and become established in Jack pine (Pinus banksiana) in Alberta, potentially threatening the boreal forest across northern Canada (Smith et al. 2011).

A variety of ophiostomatoid fungi associated with MPB have a mutually beneficial relationship with the beetle vector. Species like Grosmannia clavigerum, Leptographium longiclavatum and Ophiostoma montium are sapstaining fungi with varying degrees of pathogenicity to pine. These fungi grow quickly and stain both tree phloem and sapwood, while Ceratocystiopsis sp., a white ophiostomatoid fungus, is only found in beetle galleries. The white basidiomycete, Entomocorticium dendroctoni, whose relationship with the beetle is undefined, has also been mainly isolated from beetle galleries (Lee et al. 2006). Besides fungi and beetles, the pinewood nematode (PWN) Bursaphelenchus xylophilus, a conifer pathogen causing pine wilt disease, is considered to be indigenous to North America (Dwinell 1997). Because lodgepole pine is such a pest-prone species, green wood shipments of boards or logs to foreign or domestic markets should be allowed only after reliable pasteurization (phytosanitation) treatments.

\footnotetext{
${ }^{1}$ Department of Wood Science, The University of British Columbia, 2424 Main Mall, Vancouver, BC, V6T 1Z4, Canada.

•Corresponding author: stavros.avramidis@ubc.ca

Received: 16.04.14 Accepted: 05.06.2014
} 
Heat treatments are an alternative to fumigation with methyl bromide $\left(\mathrm{CH}_{3} \mathrm{Br}\right)$, an ozone-depleting chemical that will be soon banned for most wood products. However, treatment of green wood products with high temperature dry air result's in large moisture losses whereas steam treatments often pose major challenges, mainly because of non-uniform distribution of the heated air (Mahroof et al. 2003). Dielectric heating in general and at radio frequencies (RF) in particular, is a viable alternative heat treatment method that might alleviate these issues. This technology is not influenced by material thickness, the heating is swift and volumetric and thus, the loss of moisture is minimal, while wood is treated in batches without stickers. RF heating is successfully commercialized, cost effective and economically viable (Resch 2006).

In the current work, the effectiveness of RF heating on the survival of three types of pests - fungi, nematodes and beetles - that were naturally present or artificially inoculated into lodgepole pine boards and $\operatorname{logs}$ was tested. Processing times and energy requirements were also evaluated for a wide range of moisture contents.

\section{MATERIALS AND METHODS}

Two pilot-scale RF heating systems were used, namely, an RF-Vacuum-dryer (RFV) oscillating at 6,8 $\mathrm{MHz}$ and an RF-oven (RFO) oscillating at 40,7 MHz with corresponding wavelengths of 44,2 and 7,4 meters, respectively (Figure 1). More details about these systems may be found in Lazarescu et al. (2009).

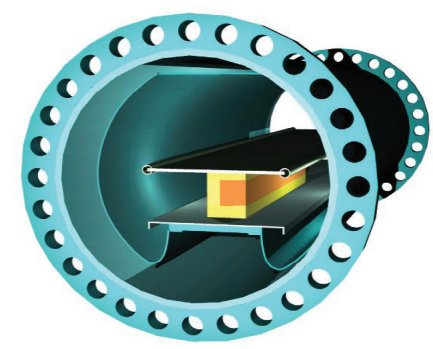

(a)

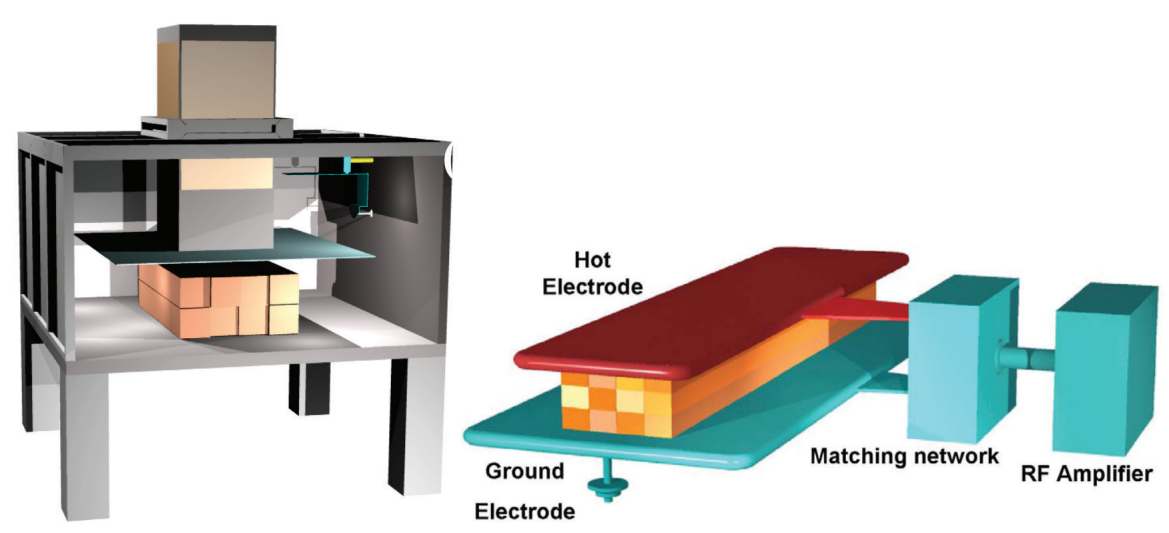

(b)

Figure 1. Computer drawings of the RFV-kiln (a) and the RF-oven oven with a cross section of the wood electrode geometry (b). 
Several MPB attacked lodgepole pine trees were harvested from an uneven-aged lodgepole pine stand located in Kelowna, BC. A large number of boards, 50x150 and 50x100 $\mathrm{mm}^{2}$ in cross-section were cut with a portable sawmill (Wood-Mizer LT15) targeting mainly the sapwood fungal colonized areas (grey to blue stained areas colonized by ophiostomatoid fungi). Some boards contained wane on one of the sides to maximize the infected board output (Figure 2).
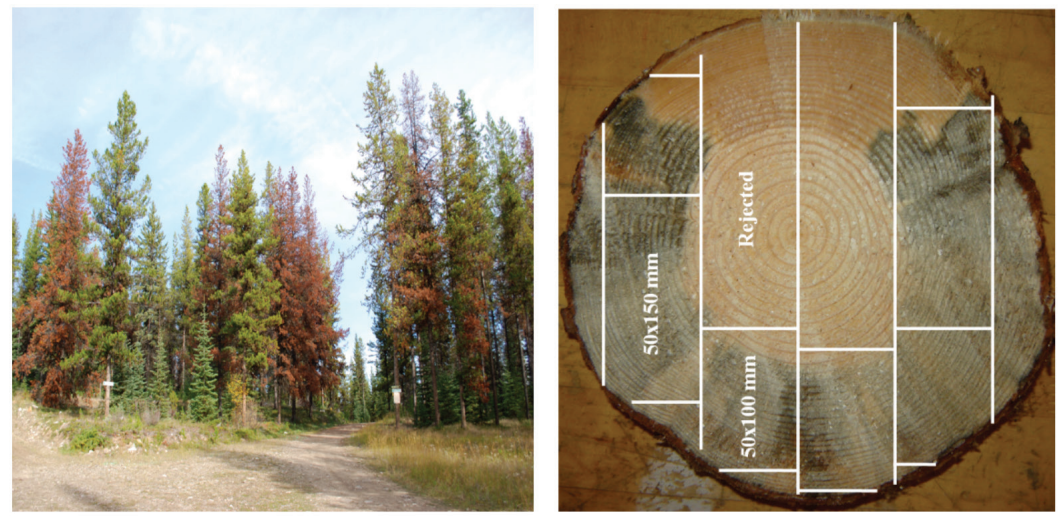

Figure 2. Targeted infected pine forest (reddish brown trees) in Kelowna, BC (left) and log cutting procedure aiming to maximize infected board output (right).

The fungal evaluation procedure consisted of sampling wood from four equidistant placed areas (Figure 3) by drilling incremental cores. The wood samples were stored for 24 hours in UV treated re-sealable plastic bags. Then, part of the cores were placed onto $1 \%$ Oxoid malt extract agar (OMEA) plates incubated at $22^{\circ} \mathrm{C}$ for 14 days for assessing the presence or absence of fungal isolates. The top and bottom 1-2 mm of the cored samples were removed to reduce airborne contamination of the specimens. Specimen items that were confirmed positive were tested either in a single or multiple specimen configuration (Figure 4).

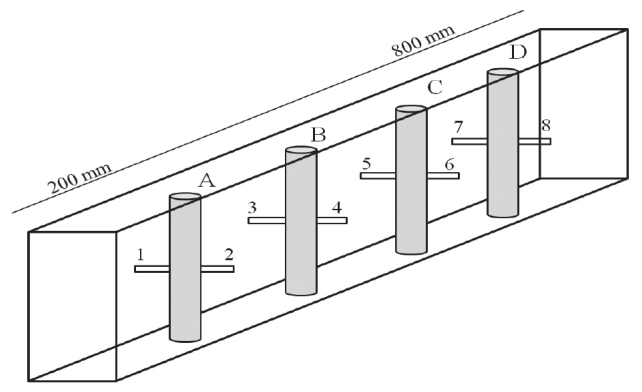

Figure 3. Pre-test drilling positions $(\mathrm{A}-\mathrm{D})$ and sensor placement $(1-8)$ in a $50 \times 100 \mathrm{~mm}$ specimen.

Filamentous ascomycetes and basidiomycetes including sapstain and decay fungi were isolated before the RF treatments. The concurrent presence of yeasts and bacteria was also assessed visually (observation of the MEA plates) and by microscopy. The presence of blue-staining fungi was supported by the growth of these fungi in the sapwood and the presence of melanized hyphae. These preliminary tests were confirmed by morphological features (e.g. conidiophores, shapes of conidia) and by DNA information; DNA was extracted from pure fungal culture. Then, the internal transcribed spacers (ITS regions) of the ribosomal DNA (rDNA) were amplified using universal ITS primers before being sent for sequencing (White et al. 1990). The acquired sequences were compared to sequences of known specimens from the University of British Columbia culture collections or from the GenBank ${ }^{\circledR}$ database. Depending on DNA sequence similarities, the fungi were identified to the genus or species. 
For single-specimen experimental runs, eight fiber optic probes (FOP) were used to monitor the temperature in all pre-tested areas (Figure 3) while for multi-specimen experiments, twelve probes were placed on the outer parts of the pile close to the pre-sampling areas. In a solid pile of boards (no stickers present), outside ones were considered to be the most vulnerable in terms of temperature drop due to water evaporation and cold air contact. Reduced treating times may be obtained if these boards are properly insulated. In order to emulate the position of a board inside a pile, each single specimen was insulated using wood boards from the same species at about $13 \%$ moisture content (MC), around all faces (Figure 4b).

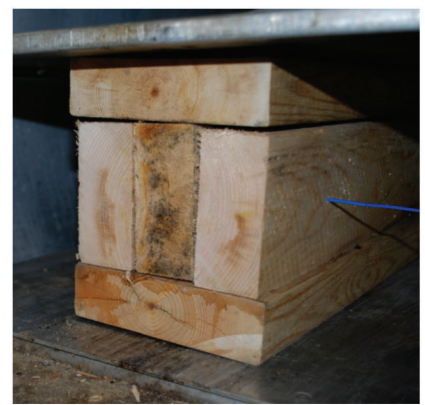

(a)

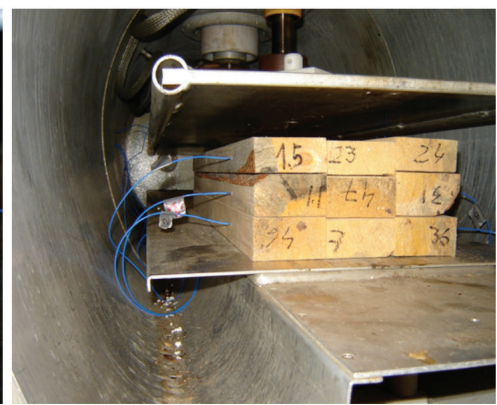

(b)

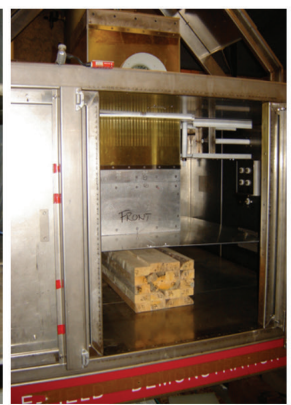

(c)

Figure 4. Test configurations for single (a) and multi-specimen arrangements (b), (c).

After the presence of fungi was confirmed, a total number of $30,50 \times 150$ and $60,50 \times 100 \mathrm{~mm}$ in cross-section infested boards were slotted for single specimen fungal experiments and 64, 50x150 were used to create three wood packages: one with 9 boards and two with 20 boards. The wood specimens were treated through RF heating either at $56^{\circ} \mathrm{C}$ for $30 \mathrm{~min}(\mathrm{RF} 56 / 30)$ or $60^{\circ} \mathrm{C}$ for $30 \mathrm{~min}(\mathrm{RF} 60 / 15)$. These time/temperature combinations were selected as optimal conditions following several preliminary tests by Lazarescu et al. (2009). Wood filamentous fungi (blue sap stain or decay fungi), yeast, bacteria and molds on each sampled area were scored as present or absent. Fungal presence from control (cores sampled before treatment) was compared to the RF-treated sections cut in the area where the sensor was installed. A ratio between controls and RF-treated samples was used to measure kill percent $\left(K_{p}\right)$, which was calculated as $K_{p}=\left[\left(R_{c c}-R_{c t}\right) / R_{c c}\right] * 100$ where $R_{c c}$ represents the ratio of contamination in controls and $R_{c t}$ is the ratio of contamination in treated wood.

A number of 76 nematode infected boards (975 mm long and 50x100 $\mathrm{mm}$ in cross section) were obtained from sound lodgepole pine logs artificially inoculated in the laboratory. The same two temperature/time combinations were tested based on the experimental protocol described in Lazarescu et al. (2011).

Twenty heavily infected logs having a diameter of $200-300 \mathrm{~mm}$ were collected from the same infested forest stand located near Kelowna (BC) during the delayed spring of 2011. Because the insect system is synchronized with the season, the lower seasonal temperature promoted all the individuals belonging to the same evolutionary stage to be equally developed (Jenkins et al. 2001). All logs were covered with silicone at both ends, in order to minimize moisture loss, and stored in an enclosed cage until adult beetles began to emerge from the logs. When the beetles started to fly around, the logs were deemed ready for pasteurization. One of the logs was debarked and the presence of live beetles and larvae was visually assessed. Since the logs were coming from the same forest from five trees that were felled in the same day, within meters one from another, it was assumed that the beetles and larvae were alive inside the bark before the test. A number of eight fiber probes were inserted close to visually identified potential infection areas (pitch tubes on the stem where beetles have entered the tree) at a depth a little below cambium layer level (drilling was stopped after bark penetration). All twenty logs were equally divided between RF56/30 and RF60/15. After pasteurization, the bark of the logs was removed to expose the adult egg and larval feeding galleries and collect the adult beetles, the tenerals (young adults not fully matured) and larvae (Figure 5). 
MC was calculated in the sensor areas by oven-dry measurements (ASTM D-4442 Method B). Power density calculations for boards and logs were done using real and imaginary dielectric measurements and electric field values were computed using Poisson Superfish (Lazarescu and Avramidis 2011, 2012).

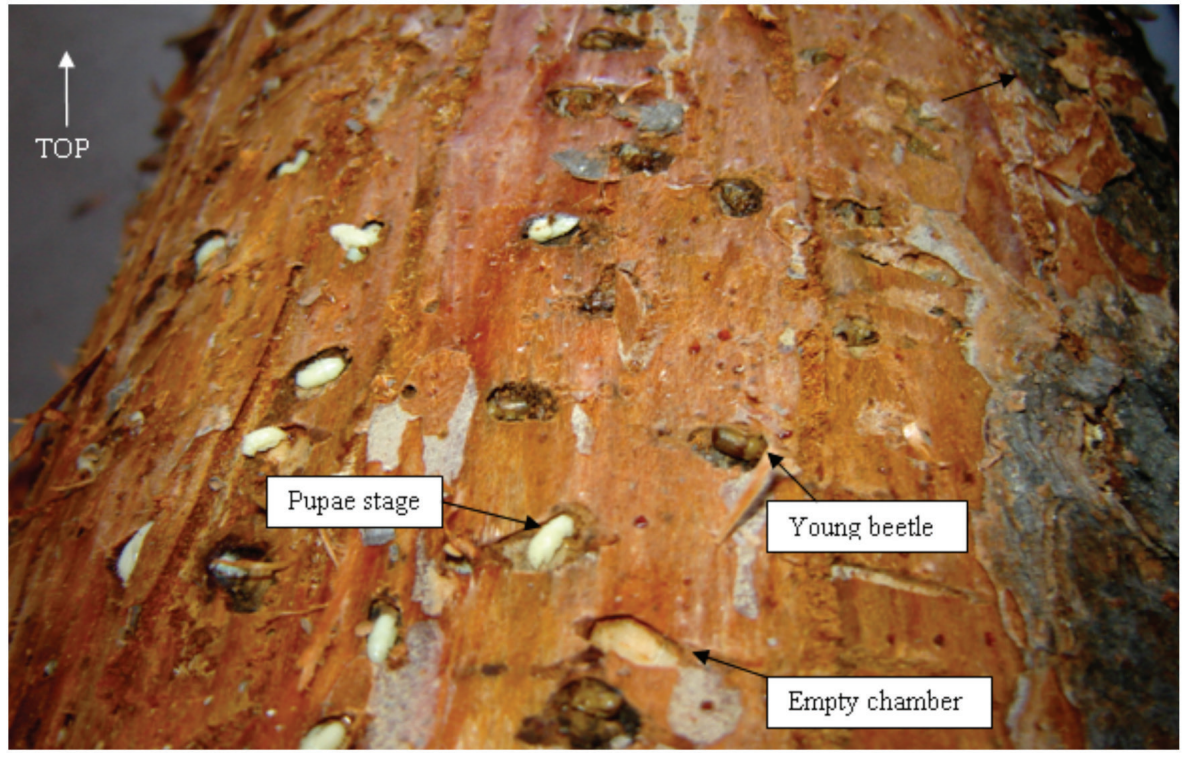

Figure 5. The bark peeled pine log full of larvae, pupae and immature adult Dendroctonus ponderosae Hopkins.

\section{RESULTS AND DISCUSSION}

The most common decay fungi identified were Byssomerulium corium, Fomitopsis pinicola, Peniophora sp., Stereum sanguinolentum and Trichaptum abietinum while the most common sapstain fungi were Grosmannia clavigera, Ophiostoma montium, Leptographium longiclavatum, Leptographium terebrantis and occasionally Ophiostoma piceae. These fungi were similar to the fungi reported by Kim et al. (2005) on attacked MPB lodgepole pines.

Internal wood damage, either honeycomb or collapse, was visually assessed by cross cuttings performed in the temperature monitored areas. No degradation was associated with the RF heating process; the MC drop did not exceed 3\% for the low MC boards (20-40\%) and 10\% for the wettest tested specimens $(\mathrm{MC}=80-100 \%)$.

In all fungi testing scenarios with single and multi-specimen configurations, was $100 \%$ for both RF56/30 and RF60/15 treatments. Nematodes (Lazarescu et al. 2011) and insects were successfully eradicated by both temperature/time combinations. An average estimated number of 88154 nematodes/ board (estimations were based on the number of nematodes per gram extrapolated to the whole board) and 8 larvae 6,5 pupae and 10 adult beetles/log were identified lifeless after the treatments.

Overall, the $\mathrm{MC}$ values in the pine lumber and logs were not very high for all the experiments testing fungi and insect infestation and survival (Table 1). These low MC's were not unexpected, as it is well established that mass attacked trees by MPB are dying and drying rapidly (Reid 1961, Kim et al. 2005). Higher MC values were tested for the nematode runs because freshly felled trees were used for artificial inoculation. 
Power density values, calculated either based on simple RF-power/wood volume ratios or using the simulated electric field values, ranged between 23 and $50 \mathrm{~kW} / \mathrm{m}^{3}$ for all types of testing configurations. The heating rates, more than 1000 were collected during the experiments, were not correlated with the overall $\mathrm{MC}$ value because of the heterogeneous $\mathrm{MC}$ distribution. That heating rate is not highly correlated with $\mathrm{MC}$ is related to the fact that more power is absorbed by the areas in need (with higher MCs) and thus the heat is uniformly redistributed; more details about heating rates and MC values in RF-fields may be found in Lazarescu et al. (2012) and Lazarescu and Avramidis (2011).

The average heating rates shown in table 1 were calculated by dividing the total time to the temperature gradient. In most of the cases the time required to increase the temperature from 56 to $60^{\circ} \mathrm{C}$ equaled or exceeded the time difference between the treatments ( 15 minutes) resulting in no clear distinction between the two from an economic point of view. Heating rate decrease with temperature raise is attributed to the increased heat capacity and thermal conductivity of wood (Skaar 1988); more details about heating rate decrease in RF-heating may be found in Lazarescu et al. 2009. As a rule of thumb higher power was generated in more energy demanding areas (high $\mathrm{MC}$ ) resulting in a more even heating process. RF-pasteurization is best adapted to logs where the targeted areas (cambium) heated faster than the rest of the material.

Table1. Power density (PD), heating rates (HR) and MC distribution for all infection levels.

\begin{tabular}{|c|c|c|c|c|c|}
\hline $\begin{array}{c}\text { Infection } \\
\text { level }\end{array}$ & $\begin{array}{c}M C \text { range } \\
{[\%]}\end{array}$ & $\begin{array}{c}P D(\text { Superfish)* } \\
{\left[\mathrm{kW} / \mathrm{m}^{3}\right]}\end{array}$ & $\begin{array}{c}P D(\mathrm{Vol})^{* *} \\
{\left[\mathrm{~kW} / \mathrm{m}^{3}\right]}\end{array}$ & $\begin{array}{c}\text { Average } \mathrm{HR} \\
{\left[{ }^{\circ} \mathrm{C} / \mathrm{min}\right]}\end{array}$ & $\begin{array}{c}\text { Total times*** } \\
{[\mathrm{min}]}\end{array}$ \\
\hline Fungi & $16,7 \ldots 55,6$ & $23,7 \ldots 46,4$ & 31,17 & $0,56 \ldots 1,91$ & $50 \ldots 98$ \\
\hline Nematodes & $22 \ldots 106$ & $34,5 \ldots 50$ & 31,17 & $0,91 \ldots 2,66$ & $42 \ldots 65$ \\
\hline Insects & $21 \ldots 48$ & $23,2 \ldots 48,4$ & 15,06 & $0,38 \ldots 1,43$ & $58 \ldots 116$ \\
\hline
\end{tabular}

* $P D$ was calculated using electric field values generated inside the material;

** PD was calculated by dividing the whole wood volume to RF power;

*** Total times were calculated for a temperature differential of $38^{\circ} \mathrm{C}$ plus $30 \mathrm{~min}$ of treatment. 


\section{CONCLUSION}

Based on the results, lodgepole pine infested boards and logs at different degrees with fungi, nematodes and insects, was successfully sterilized through high frequency heating by using two temperature/time combinations: $56^{\circ} \mathrm{C} / 30 \mathrm{~min}$ and $60^{\circ} \mathrm{C} / 15 \mathrm{~min}$. A power density ranging from 23 to $50 \mathrm{~kW} /$ $\mathrm{m}^{3}$ for 42 to up to 116 minutes pasteurized all pest and wood type combinations tested.

\section{ACKNOWLEDGEMENTS}

This work was financially supported by a Strategic Grant from the Natural Sciences and Engineering Research Council of Canada.

\section{REFERENCES}

Dwinell, L.D. 1997. The Pine Wood Nematode: Regulation and Mitigation. Annu Rev Phytopathol 35: 153-66.

Garas, N.A.; N. Doke; Kuc. J. 1979. Suppression of the hypersensitive reaction in potato tubers by mycelial components from Phy-tophthora infestans. Physiol Plant Pathol 15: 117-126.

Jenkins, J.L.; Powell, J.A.; Logan, J.A. 2001. Low seasonal temperature promotes life cycle synchronization. Bulletin of Mathematical Biology 63(3):573-595.

Khadempour, L; Massoumi Alamouti, S.; Hamelin, R.C.; Bohlmann, J.; Breuil, C. 2010. Target specific PCR primers can detect and differentiate ophiostomatoid fungi from microbial communities associated with the mountain pine beetle Dendroctonus ponderosae. Fungal Biology 114: 825-833.

Kim, J.J.; Allen, E.A.; Humble, L.M.; Breuil, C. 2005. Ophiostomatoid and basidiomycetous fungi associated with green, red, and grey lodgepole pines after mountain pine beetle (Dendroctonus ponderosae) infestation. Can J For Res 35: 274-284.

Lazarescu, C.; Avramidis, S. 2011. Radio- frequency heating kinetics of softwood logs. Drying Technology 29(6): 673-681.

Lazarescu, C.; Avramidis, S. 2012. Heating characteristics of western hemlock (Tsuga heterophylla) in a high frequency field. Eur J Wood Prod 70: 489-496.

Lazarescu, C.; Bedelean B.; Avramidis, S. 2012. Heating Characteristics of Softwoods in a High Frequency Field. PRO Ligno 8(4): 18-26.

Lazarescu, C.; Dale, A.; Uzunovic, A.; Avramidis, S. 2011. Radio Frequency Heating Pasteurization of Pine Wood Nematode (Bursaphelenchus xylophilus) Infected Wood Eur. J Wood Prod 69(3): 573-578.

Lazarescu, C.; Plattner, A.; Hart, F.; Breuil, C.; Avramidis, S. 2009. Pasteurization of Hemlock by Radio Frequency Heating: A preliminary study. Forest Prod J 59(4): 79-83.

Lee, S.; Jae-Jin, K.; Breuil C. 2006. Diversity of fungi associated with the mountain pine beetle, Dendroctonus ponderosae and infested lodgepole pines in British Columbia. Fungal Diversity 22: 91-105.

Mahroof, R.; Subramanyam, BH.; Eustace, D. 2003. Temperature and relative humidity profiles during heat treatment of mills and its efficacy against Tribolium castaneum (Herbst) life stages. $J$ Stored Prod Res 39: 555-569. 
Nikiforuk, A. 2007. Pine plague. Canadian Geographic 127 (1): 68-76.

Reid, R.W. 1961. Moisture changes in lodgepole pine before and after attack by the mountain pine beetle. Forestry Chronicle 37(4): 368-403.

Resch, H. 2006. High- frequency electric current for drying of wood - Historical perspectives. Maderas Cienc Tecnol 8(2): 67-82.

Skaar, C. 1988. Wood-Water Relations. Springer-Verlag, New York.

Smith, G.D.; Carroll, A.L.; Lindgren, B.S. 2011. Facilitation in bark beetles: endemic mountain pine beetle gets a helping hand. Agricultural and Forest Entomology 13: 37-43.

White, T.J.; Bruns, T.D.; Taylor, J.W. 1990. Amplification and direct sequencing of fungal ribosomal RNA genes for phylogenetics. In: PCR Protocols, Methods and Amplifications (Innis, M.A., Gelfand, D.H., Sninsky, J.J. and White, T.J., Eds.), pp. 315-322. Press, San Diego, CA.

Williamson, T.B.; Colombo, S.J.; Duinker, P.N.; Gray, P.A.; Hennessey, R.J.; Houle, D.; Johnston, M.H.; Ogden, A.E.; Spittlehouse, D.L. 2009. Climate change and Canada's forests: from impacts to adaptation. Sustain. For. Manag. Netw. And Nat. Resour. Can., Can. For. Serv., North. For. Cent., Edmonton, AB. 